\title{
OS PROCESSOS DE APRENDIZAGEM ORGANIZACIONAL E A INOVAÇÃO: UM ESTUDO DE CASO LONGITUDINAL (1986-1995) EM UMA EMPRESA DO SETOR PETROLÍFERO BRASILEIRO
}

\section{THE PROCESSES OF ORGANIZATIONAL LEARNING AND INNOVATION: A LONGITUDINAL CASE STUDY (1986-1995) IN A COMPANY OF BRAZILIAN OIL SECTOR}

\author{
José Antônio Valle Antunes Júnior* E-mail: junico@unisinos.br \\ Ivan de Pellegrin ${ }^{* *}$ E-mail: pellegrin@produttare.com.br \\ Rodrigo Pinto Leis ${ }^{* *}$ E-mail: rodrigo@produttare.com.br \\ Marco V. Zimmer*** E-mail: zim@uol.com.br \\ Guilherme Luís Roehe Vaccaro* E-mail: guilhermev@unisinos.br \\ Daniel Pacheco Lacerda* E-mail: dlacerda@unisinos.br \\ *Universidade do Vale do Rio dos Sinos - UNISINOS, São Leopoldo, RS \\ ${ }^{* *}$ Produttare Consultores Associados, Porto Alegre, RS \\ ***Faculdade de Administração de Brasília, Brasília, DF
}

\begin{abstract}
Resumo: A inovação é um dos fatores importantes para as empresas. No presente estudo, verificouse como ocorrem os processos de aprendizagem organizacional voltados à inovação em uma empresa da indústria petrolífera. O método de trabalho utilizado foi o Estudo de Caso. Para a realização da pesquisa, que teve caráter exploratório, foram realizadas entrevistas com profissionais ligados a história da empresa. Os relatos a respeito dos processos de inovação foram descritos por meio de análise de conteúdo e, após, relacionados com a tipologia de inovação proposta por Schumpeter (1942), com os tipos de aprendizagem de Malerba (1992), com os modos de aprendizagem single e double loop de Argyris e Schön (1978), com as formas de conversão de conhecimento de Nonaka e Takeuchi (1997) e com os espaços de criação do conhecimento de Nonaka et al. $(1998,2000)$. Os resultados da pesquisa indicam que inovações radicais, de modo geral, demandam uma gama maior de estilos de aprendizagem, em comparação com inovações incrementais. A internalização e a socialização tendem a predominar em inovações radicais. Já a externalização e combinação são mais freqüentes nas inovações incrementais. Finalmente, os resultados apontam para o fato de que as aprendizagens do tipo single loop são relacionadas mais diretamente a inovações incrementais, ao passo que as de double loop são mais encontradas em inovações radicais.
\end{abstract}

Palavras-chave: Inovação. Aprendizagem Organizacional. Criação de Conhecimento. Indústria Petrolífera.

Abstract: Innovation is one important factor for companies. This study presents a longitudinal case study focusing on the learning processes associated to innovation on an oil industry company. To conduct the study, which was of exploratory nature, interviews were conducted with professionals connected to the history of the company. Reports about the processes of innovation were described by content analysis and related to: the types of innovation proposed by Schumpeter (1942); the types of learning proposed by Malerba (1992); the modes of learning single loop and double loop of Argyris and Schön (1978); the ways of knowledge conversion of Nonaka and Takeuchi (1997); and the creation of spaces of knowledge of Nonaka et. al $(1998,2000)$. The research results indicate that 
radical innovation tends to require a wider range of learning styles, if compared to incremental innovations. Still, the internalization and socialization seems to prevail in contexts of radical innovation, while externalization and combination are more frequent in incremental innovation contexts. Finally, the results point to the fact that the single loop learning is more directly related to incremental innovations, while the double loop learning is more present in radical innovation contexts.

Keywords: Innovation. Organizational Learning. Creation Of Knowledge. Oil Industry.

\section{INTRODUÇÃO}

Inovar constitui-se em um dos elementos fundamentais para a diferenciação das empresas em relação à concorrência. Portanto, a geração sistemática de inovação nas empresas merece ser abordada sob o prisma teórico e prático. Esse assunto é particularmente relevante no ambiente brasileiro, onde a tradição da prática de inovação ainda necessita ser incorporada ao cotidiano das organizações. Dentre as possíveis explicações, para as dificuldades das empresas brasileiras realizarem sistematicamente inovações, estão os aspectos de cunho tecnológico, organizacional e institucional.

Hamel e Getz (2004) afirmam que, dentre os recursos escassos para gerar inovação nas empresas, está a formação dos gestores. Inovar implica na necessidade de formar quadros/profissionais qualificados, considerando que os recursos econômicos disponíveis para investimento são escassos. Uma hipótese geral a ser explorada diz respeito à alocação eficaz dos recursos destinados à inovação nas empresas e sua dependência da capacidade de gestão desses recursos. Assim, compreender conceitualmente o tema da inovação parece constituir-se em um passo importante em dois sentidos. Em um sentido, na percepção dos detentores do capital de que existe a necessidade objetiva da inovação para alavancar a competitividade das empresas. Em outro sentido, observar como construir processualmente os elementos de gestão que podem permitir a sistematização do tema no ambiente interno das organizações.

Princípios essenciais da inovação eficaz são a simplicidade e o foco (OSONO, SHIMIZU e TAKEUCHI, 2008). O esforço de inovação deve estar direcionado para uma aplicação específica e projetado no intuito de criar novos usuários e mercados (aqui entendido como produtos e geografia). Cabe destacar que a inovação pode ser um ato mais de esforço do que inspiração, exigindo um misto de conhecimento, persistência e engenhosidade. É possível, ainda, inferir que 
o empreendedorismo envolve mais que a inovação sistemática. Contudo, percebese certa correlação entre o empreendedorismo e a prática de inovação sistemática nas empresas.

Para Druker (1985) a inovação é o trabalho de 'saber' e não de 'fazer'. Druker (1985), a partir de uma base empírica, afirma que a maioria das idéias inovadoras nos negócios deriva de sete áreas de oportunidades. Dentre estas, quatro são internas a empresa ou setor: (1) ocorrências inesperadas; (2) incongruências; (3) necessidades de processos; e (4) mudanças setoriais e de mercado. Outras três fontes de oportunidades são externas a empresa, em seu ambiente social e intelectual: (5) mudanças demográficas; (6) mudanças em percepção; e (7) novos conhecimentos. Todas estas fontes são relevantes para a inovação, sendo que o potencial de inovação está simultaneamente intrínseco em mais de uma delas.

O campo de estudos em torno da inovação está em construção. Para uma tentativa de delineamento de um modelo empresarial voltado à inovação, a partir da literatura especializada da área, foram identificadas algumas perspectivas da inovação. Dentre as perspectivas mapeadas, destacam-se as seguintes: 1 perspectiva de estrutura organizacional de gestão (KANTER, 1982; MILLER e MORRIS, 1998; SHANLEY, 1998; DAY e SCHOEMAKER, 2000); 2 - perspectiva de relacionamento com o ambiente externo (MILLER e MORRIS, 1998; DAY e SCHOEMAKER, 2000); 3 - perspectiva de processos, práticas e métodos (MILLER e MORRIS, 1998; DAY e SCHOEMAKER, 2000; TRIPSAS, 2000; GOLDENBERG e MAZURZKY, 2001; WOOD e HAMEL, 2002; ANDREW e SIRKIN, 2003; GOLDENBERG et al., 2003; THOMKE, 2003; MOORE, 2004; CHAKRAVORTI, 2004;; et al.;); 4 - perspectiva de indicadores de desempenho (GEISLER, 2000; CIDEM, 2002); 5 - perspectiva estratégica (KIM e MAUBORGNE, 1997; DAY e SCHOEMAKER, 2000; DYER e SINGH, 2000; RUELAS-GOSSI, 2004; HAMMER, 2004); 6 - perspectiva legal ( TRIPSAS, 2000; CHAMAS, 2003; ANAND e GALETOVIC, 2004); 7 - perspectiva financeira e de financiamento (MILLER e MORRIS, 1998; SVEIBY, 1998; ALLEN e PERCIVAL, 2000; HAMILTON, 2000; SCHOEMAKER e SHAPIRO, 2000; ROBERTS, 2003; ); e 8 - perspectiva de conhecimento (DRUCKER, 1985; DAVENPORT e PRUSAK, 
1998; DAY e SCHOEMAKER, 2000; TRIPSAS, 2000; BUKOWITZ e WILLIAMS, 2002; PROBST et al., 2002; ).

Pode-se especular que o tema da inovação obtém cada vez mais espaço nos debates acadêmicos e empresariais. No entanto, como um processo intrínseco do avanço científico, existem lacunas a serem preenchidas e melhor exploradas no que tange ao corpo de conhecimento relativo à inovação. Uma das lacunas identificadas diz respeito à forma pela qual ocorre o processo da aprendizagem organizacional direcionado para a inovação. Assim, a organização que deseja inovar, provavelmente, deveria preocupar-se em "aprender a aprender". Isso decorre do fato de que o esforço de inovação requer, em suas diversas ações, níveis de aprendizagem com graus de complexidade distintos. Algumas situações acarretam uma mudança tanto em nível de indivíduo (os colaboradores da empresa) quanto da organização. Assim sendo, a questão que motiva a realização deste artigo pode ser explicitada da seguinte maneira: 'Como ocorre a aprendizagem organizacional em empresas que buscam inovar sistematicamente'?

A partir dessa questão, em função da necessidade de exploração no tema, o objetivo central deste trabalho consiste em verificar como ocorrem os processos de aprendizagem organizacional voltados à inovação em um contexto específico. Nesse caso, uma empresa pertencente à cadeia produtiva da indústria petrolífera brasileira. Para isso, se identifica o contexto empresarial específico para compreender os processos de aprendizagem organizacional necessários à inovação. Também são levantados dados e informações sobre os processos de aprendizagem verificados no caso selecionado. Por fim, são classificados os tipos de processo de aprendizagem organizacional em relação às inovações geradas.

$\mathrm{Na}$ tentativa de produzir avanços, no que tange ao questionamento proposto, o artigo se estrutura apresentando inicialmente alguns elementos teóricos enfatizando os principais conceitos de inovação, aprendizagem organizacional e processos de aprendizagem organizacional. Em seguida se formaliza o método de pesquisa e seus instrumentos para coleta e análise dos dados. Na seqüência, se contextualiza a empresa e se realiza a descrição do Estudo de Caso. Na sequência, partindo dos resultados obtidos, são realizadas a análise, a discussão e a síntese dos resultados. Finalmente, são apresentadas as principais conclusões do artigo. 


\title{
2 REFERENCIAL TEÓRICO
}

\subsection{A Inovação}

Schumpeter (1942) destaca que as mudanças da vida econômica de uma empresa não Ihe são impostas exogenamente. Pelo contrário, Schumpeter (1942) propugna que as mudanças em termos da competitividade da empresa ocorrem por sua "própria iniciativa" do tipo empreendedora que, aliada ao seu poder de investimento (crédito), é capaz de criar um novo empreendimento com maior lucratividade. Além disso, as mudanças causadas no âmbito da empresa alteram o estado de equilíbrio pré-existente, jogando-o para um novo estado, o da "destruição criadora". Este fenômeno pode ser intitulado de inovação. O termo inovação possui diferentes definições sem necessariamente haver na literatura um único conceito dê conta de suas perspectivas. Alguns conceitos de inovação são ilustrados a partir de Simantob e Lippi (2003, p. 10):

\begin{abstract}
A Inovação pode ser vista como um processo de aprendizagem organizacional (Martin Bell e Keith Pavitt - Universidade de Sussex).

Inovação é adotar novas tecnologias que permitem aumentar a competitividade da companhia (C.K. Prahalad - Universidade de Michigan). Inovação é uma nova idéia implementada com sucesso, que produz resultados econômicos (Ernest Gundling - 3M).

Inovação é o ato de desenvolver novas capacidades com os recursos (pessoas e processos) existentes na empresa para gerar riqueza (Peter Drucker - Universidade de Claremont).

Inovação é um processo de alavancar a criatividade para criar valor de novas maneiras, por meio de novos produtos, novos serviços e novos negócios (Ronald Jonash e Tom Sommerlatte.
\end{abstract}

Nesse sentido se pode afirmar que alguns aspectos relevantes relacionados ao conceito de inovação são: (i) a idéia de que a inovação está associada diretamente com a competitividade das empresas; (ii) a noção de que a inovação é essencial para abrir novos mercados(entendidos como novos produtos no mesmo espaço geográfico ou os mesmos produtos em novos espaços geográficos ou, ainda, novos produtos em novos espaços geográficos); e (iii) a perspectiva de que a inovação está associada com a criatividade individual, em particular, e com a aprendizagem organizacional, em geral.

Percebe-se, também, que a necessidade de uma política de inovação surgiu como um elemento que permite articular as políticas de ciência e tecnologia, 
industrial e de comércio exterior de um país (a Lei Nacional 10.973/2004 e a Lei Estadual 13.196/2009, por exemplo). Uma política de inovação sinaliza o reconhecimento de que o conhecimento desempenha um papel importante no progresso econômico e a inovação tem centralidade em uma economia baseada nesse ativo. A abordagem sistêmica da inovação desloca o foco da política na direção da ênfase na interação entre instituições, concentrando-se nos processos interativos da criação do conhecimento, assim como de sua difusão e aplicação (OECD, 1997).

Schumpeter (1942) afirmava que a concorrência não ocorreria via preços, mas pelo lucro obtido pela inovação. Por conseqüência, existe a necessidade de investimentos em Pesquisa e Desenvolvimento (P\&D) na tentativa de manter e aumentar o lucro, sendo, portanto, a atividade de inovação parte constituinte central da atividade econômica. O que era uma necessidade das organizações (buscar na ciência o auxílio para solucionar problemas na produção) transforma-se em algo crítico no que tange a competitividade das empresas atuais.

A inovação apresenta diferentes tipos de tipologias. Schumpeter (1942) destaca os seguintes tipos gerais de inovações: (i) introdução de um novo produto ou mudança qualitativa em produto existente; (ii) inovação de processo que seja novidade para uma indústria; (iii) abertura de um novo mercado; (iv) desenvolvimento de novas fontes de suprimento de matéria-prima ou de outros insumos; e; (v) mudanças na organização industrial. Outra forma de classificação da inovação é em relação ao grau da inovação subdividida em: inovação radical ou descontínua (aquelas que provocam grandes mudanças no mundo) e inovação incremental ou contínua - pequenas mudanças de melhoria, mas efetuadas sistematicamente (CHRISTENSEN e RAYNOR, 2003).

A Figura 1 apresenta uma tipologia de inovação dentro do contexto de uma cadeia de valor e suas atividades. Algumas inovações, como o processo de lançar novos produtos no mercado, por exemplo, pode envolver a cadeia de valor como um todo. Entretanto, em alguns pontos dessa cadeia a apropriação do valor gerado pela inserção desses produtos no mercado é maior que em outros. Assim, tipos de diferentes de inovação são requeridos nos diversos pontos da cadeia de valor. Além disso, a Figura 1 mostra que a atividade de inovação precisa basear-se em um 
sistema de gestão da inovação e em uma lógica estruturada de financiamento das atividades de inovação.

Figura 1 - Apropriação do valor ao longo da cadeia de inovação.

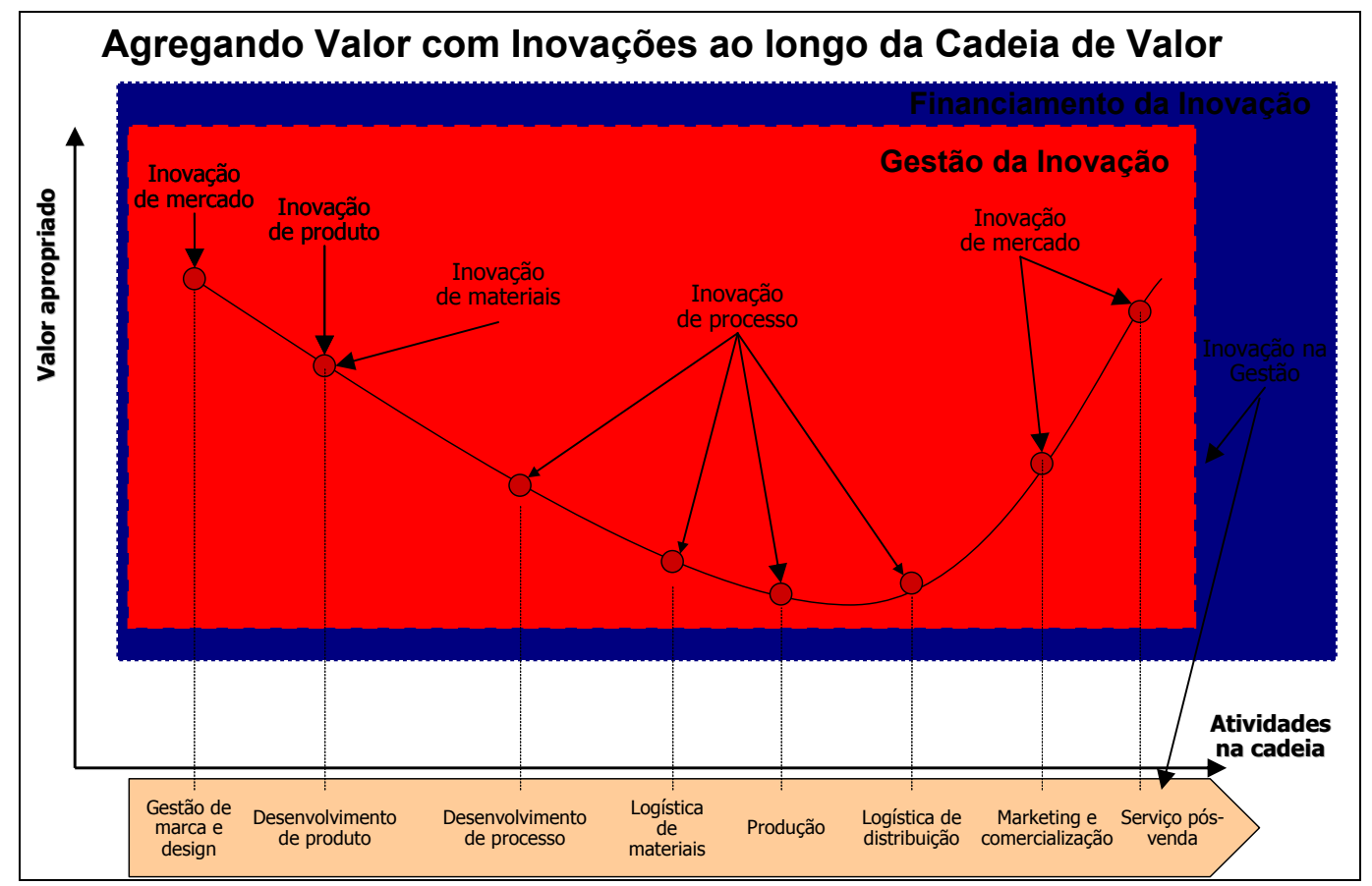

Fonte: Antunes, Pantaleão e Pellegrin (2007)

\subsection{A inovação e os Tipos de Aprendizagem nas Organizações}

Malerba (1992) e Scheffer e Schenini (2004) abordam a questão da aprendizagem como elemento central no processo de inovação e criação de riqueza das firmas. Destaca-se, nesse contexto, a característica da cumulatividade, pela qual a prática repetitiva e a experimentação permitem a realização ágil e eficaz das tarefas, reduzindo os "elementos de incerteza", pois "traduzem um conhecimento prévio tanto das tecnologias em uso, quanto dos mercados nos quais atuam" (SCHEFFER e SCHENINI, 2004, p.3). Segundo essa visão, a aprendizagem organizacional caracteriza-se por qualquer aprendizado obtido pela organização podendo ser expresso, por exemplo, por meio de rotinas de trabalho.

Malerba (1992) sintetiza os principais tipos de aprendizagem a partir de um estudo no qual relaciona a aprendizagem nas empresas com mudanças técnicas incrementais. Nesse trabalho, o aprendizado é apresentado como interno ou externo às organizações e relacionado a diferentes processos, fatores ou elementos, como atividades de produção, pesquisa e desenvolvimento, e a diferentes formas de 
interação e/ ou cooperação entre firmas, por exemplo. O Quadro 1 sintetiza essa tipologia.

Esta tipologia é relevante - Quadro 1 - no escopo do presente estudo, na medida em que permite elaborar relacionamentos entre os modos de aprendizado com autores voltados à Aprendizagem Organizacional, que serão vistos a seguir.

Quadro 1 - Tipologias de Aprendizagem

\begin{tabular}{|l|c|l|}
\hline \multicolumn{1}{|c|}{ Tipo de aprendizagem } & $\begin{array}{c}\text { Nível à } \\
\text { organização }\end{array}$ & \multicolumn{1}{c|}{ Relacionada a/ao } \\
\hline $\begin{array}{l}\text { Aprendizagem pelo fazer (by } \\
\text { doing) }\end{array}$ & Interno & Atividade de produção \\
\hline Aprendizagem por uso (by using) & Interno & Uso de produtos, maquinário e inputs \\
\hline $\begin{array}{l}\text { Aprendizagem por pesquisa (by } \\
\text { searching) }\end{array}$ & Interno & $\begin{array}{l}\text { Atividades formalizadas (como P\&D) } \\
\text { orientadas à geração de novos conhecimentos }\end{array}$ \\
\hline $\begin{array}{l}\text { Aprendizagem a partir de avanços } \\
\text { em ciência e tecnologia }\end{array}$ & Externo & $\begin{array}{l}\text { Absorção de novos desenvolvimentos em } \\
\text { ciência e tecnologia }\end{array}$ \\
\hline $\begin{array}{l}\text { Aprendizagem a partir de } \\
\text { excedentes inter- indústrias (from } \\
\text { inter-industry spillovers) }\end{array}$ & Externo & $\begin{array}{l}\text { O que competidores e outras firmas na } \\
\text { indústria estão fazendo }\end{array}$ \\
\hline $\begin{array}{l}\text { Aprendizagem por interação (by } \\
\text { interacting) }\end{array}$ & Externo & $\begin{array}{l}\text { Interação com fontes de conhecimento } \\
\text { diversas, como fornecedores ou usuários, ou } \\
\text { cooperação com outras firmas na indústria. }\end{array}$ \\
\hline
\end{tabular}

Fonte: Malerba (1992, p. 14)

\subsection{Aprendizagem Organizacional}

Os temas aprendizagem organizacional, ou organizações que aprendem, são tratados no campo da administração e da engenharia de produção. O debate epistemológico em busca de uma maior convergência conceitual vem crescendo (PRANGE, 2001; CLEGG et al., 2005; FRIEDMAN et al., 2005). As fronteiras entre aprendizagem organizacional e organizações que aprendem, rígidas há alguns anos, vêm diminuindo (CHIVA e ALEGRE, 2005). As discussões sobre o caráter prescritivo e descritivo dessas linhas vêm ganhando corpo (TSANG, 1997). A seguir são apresentados alguns elementos teóricos dessas discussões. 


\section{a) Aprendizagem por Circuito Simples (Single Loop Learning) e Aprendizagem por Circuito Duplo (Double Loop Learning)}

Christensen e Raynor (2003) classificam as inovações em incrementais e radicais. Nesse sentido, a classificação aproxima-se dos conceitos de aprendizagem por circuito simples (Single Loop Learning) e duplo (Double Loop Learning) (ARGYRIS e SCHÖN, 1978). A aprendizagem no circuito simples seria aquela que gera uma pequena melhoria - incremental, segundo Christensen e Raynor (2003) sem, contudo, afetar necessariamente os resultados de uma organização. Argyris e Schön (1978) citam o caso de inspetores de qualidade que identificam um determinado problema na fabricação de um produto, passam essa informação ao grupo de engenheiros e, com isso, é gerada uma modificação no processo para corrigir o defeito. Nesse ponto pode-se traçar um paralelo com o conceito de inovação incremental de Christensen e Raynor (2003). A Figura 2 representa esses dois tipos de aprendizagem, a partir dos elementos princípios, ação e resultados.

Figura 2 - Single e Double Loop Learning

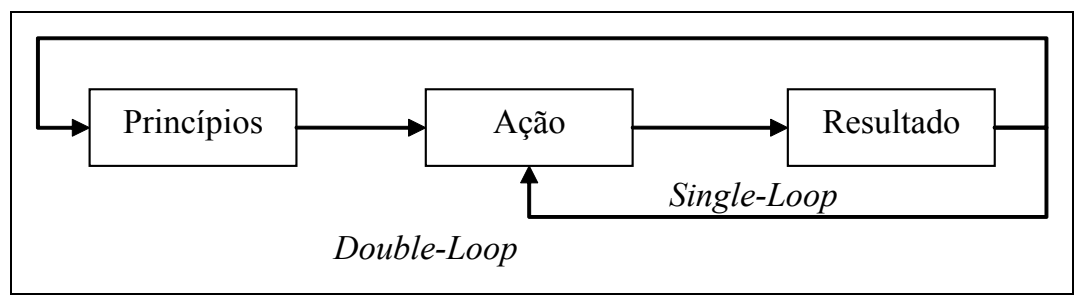

Fonte: Argyris (1993).

A aprendizagem no circuito duplo é aquela ocasionada pela revisão dos princípios orientadores, passaria pela revisão do processo e, ao final, geraria alguma espécie de resultado para a organização. As diferenças, neste caso, passam pela questão da revisão dos princípios, normas, políticas e objetivos, e pela materialização da ação e sua transformação em resultados organizacionais. "O double loop se refere aos dois circuitos de feedback que conectam os efeitos observados da ação com estratégias e valores servidos pelas estratégias" (ARGYRIS e SCHÖN, 1978, p. 21). Neste caso, haveria uma inovação do tipo radical, por exemplo. 
Cada uma destas formas de aprendizagem possui alguns valores inerentes, estratégias de ação e resultados de aprendizado que são gerados a partir de sua mobilização. O Quadro 2 apresenta um resumo desses fatores, delineando suas principais características.

Quadro 2 - Características da aprendizagem single loop e double loop

\begin{tabular}{|c|l|l|}
\cline { 2 - 3 } \multicolumn{1}{c|}{} & \multicolumn{1}{c|}{ Single loop } & \multicolumn{1}{c|}{ Double loop } \\
\hline & - ter controle unilateral das & - utilizar informações válidas \\
- dar às pessoas o direito de optar livremente \\
situações
\end{tabular}

Fonte: Argyris (1999)

\section{b) Formas de Conversão do Conhecimento e o Conceito de BA}

As formas de aprendizagem e de geração de conhecimento nas organizações são temas de pesquisa nas organizações. Nonaka e Takeuchi (1997) desenvolveram um modelo que parte de formas de interação entre conhecimento para a conversão e criação do conhecimento organizacional, denominando-o processo SECl (A sigla faz alusão às iniciais das quatro formas de conversão: $\mathrm{S}$, de socialização, E, de externalização, C, de combinação, e I, de internalização ). Assim, a interação entre conhecimento tácito com outro conhecimento tácito constituiria a socialização; o conhecimento tácito em explícito, externalização; o 
conhecimento explícito em explícito, combinação, e o explícito em tácito, internalização. O Quadro 3 ilustra essas formas de conversão.

Quadro 3 - O modelo de Nonaka e Takeuchi de conversão do conhecimento

\begin{tabular}{|l|c|c|}
\cline { 2 - 3 } \multicolumn{1}{c|}{} & Conhecimento Tácito & Conhecimento Explícito \\
\hline Conhecimento Tácito & Socialização & Externalização \\
\hline Conhecimento Explícito & Internalização & Combinação \\
\hline
\end{tabular}

Fonte: Nonaka e Takeuchi (1997)

A partir da interação entre essas formas de conhecimento, iniciado no nível individual, o conhecimento é transformado, perpassando dimensões ontológicas diversas: equipes, organizações e, até mesmo, o nível interorganizacional. Essa conversão contínua, perpassando diversos níveis, geraria a espiral do conhecimento organizacional - constituindo, assim, o cerne do modelo.

Nonaka et al. $(1998,2000)$ ampliam esse conceito original, inserindo um novo elemento: o espaço necessário à criação do conhecimento. Alegando que, para tal, o processo de criação do conhecimento necessita de um contexto específico, utilizam-se da expressão japonesa ba (que, em uma tradução aproximada, significaria 'lugar') para denominar essa dimensão, conceituando-a como "o contexto no qual o conhecimento é compartilhado, criado e utilizado" (NONAKA et al., 2000 , p. 14). Cabe ressaltar que esse lugar não seria necessariamente físico, mas também virtual - tanto o espaço de compartilhamento de modelos mentais quanto aqueles relacionados à Internet, como o e-mail, por exemplo. Assim, haveria quatro tipos de ba: originating ba, espaço de interação individual e face a face, dialoguing ba, coletivo e face e face, systemising ba, coletivo e virtual, e exercising ba, individual e virtual. O Quadro 4 ilustra esses tipos de espaço.

Quadro 4 - Os quatro tipos de $B a$

\begin{tabular}{|c|c|c|c|}
\hline \multicolumn{2}{|c|}{ Tipo de Interação } & Individual & Coletiva \\
\hline \multirow{2}{\circ}{} & Face a Face & Originating $\mathbf{B a}$ & Dialoguing $\mathbf{B a}$ \\
\cline { 2 - 4 }$\Sigma$ & Virtual & Exercising $\mathbf{B a}$ & Systemising $\mathbf{B a}$ \\
\hline
\end{tabular}

Fonte: Nonaka et al., 2000.

A seguir é apresentado o método utilizado para a condução da pesquisa. 


\section{MÉTODO DE PESQUISA}

Dentro da abordagem qualitativa há diferentes métodos de investigação, dentre esses se encontram os Estudos de Caso (GODOY, 1995b). O Estudo de Caso é um método de investigação que se caracteriza pela análise aprofundada de uma determinada realidade. Estudos de Caso são recomendados quando se colocam questões do tipo "como" e "por que", quando o pesquisador tem pouco controle sobre os eventos e quando o foco se encontra em fenômenos contemporâneos inseridos em algum contexto da vida real. (YIN, 2005; AMATURANGA et al., 2001). Segundo Dubé \& Paré (2003) os Estudos de Caso são apropriados quando o objeto de investigação é complexo, é necessária uma visão do todo e quando o fenômeno estudado não pode ser analisado fora do contexto onde ocorre. Esse método de investigação também é apropriado nos casos onde é necessária profundidade na pesquisa (DUBÉ \& PARÉ, 2003; EINSENHARDT, 1989). Einsenhardt (1989) argumenta e apresenta ainda possibilidades do Estudo de Caso para a construção de teorias.

Pelas características apresentadas pelo Estudo de Caso e as dimensões já discutidas até o momento esse método de investigação enquadra-se para os objetivos desse trabalho. Além disso, para Ellram (1996) o Estudo de Caso pode ser utilizado para: (1) explorar um determinado assunto ou problema, entendendo-o profundamente; (2) explanar sobre um fenômeno; (3) descrever um fenômeno; e (4) predizer características de um determinado fenômeno. Alguns dos propósitos para o uso do Estudo de Caso descrito por Ellram (1996) justificam a utilização desse método para esta pesquisa.

A presente pesquisa é caracterizada como um Estudo de Caso de natureza exploratória. A natureza exploratória é definida por sua aplicabilidade ao estudo de temas em novas áreas ou quando se pretende fazer emergir teoria a partir de determinada situação (ROESCH, 1999).

Para o desenho do Estudo de Caso foram utilizadas fontes primárias e secundárias. As fontes primárias constituíram-se de entrevistas semi-estruturadas com três respondentes: o primeiro, um estudioso da temática inovação, que teve 
acesso a informações sobre a Rede Petro-RS ${ }^{1}$ e às empresas envolvidas na mesma. Esse primeiro momento serviu para definir em qual das empresas desse arranjo produtivo seriam feitas as entrevistas para as fases seguintes, ou seja, para selecionar uma empresa que tivesse como estratégia de atuação a busca contínua da inovação. O segundo respondente foi um dos ex-executivos da empresa selecionada, com papel ativo e decisivo, no período de tempo selecionado para a pesquisa, das negociações e processos de tomada de decisão relativos aos processos de inovação ocorridos nessa organização. O terceiro entrevistado, um funcionário do segmento tático da empresa, que participou diretamente na implementação e na execução técnica dos projetos relacionados à inovação ora relatados. A premissa que guiou a seleção do segundo e do terceiro entrevistados foi cobrir dois diferentes segmentos de uma organização, quais sejam, o tático e o estratégico. Ao mesmo tempo, partiu-se do pressuposto que visões de funcionários desses dois níveis poderiam fornecer informações complementares ou, até mesmo, apontar divergências de percepção em relação às situações relatadas.

A noção de entrevista semi-estruturada refere-se à criação de um conjunto de perguntas-guia, a partir da revisão teórica realizada, apontando para questões relacionadas à inovação, aprendizagem e construção do conhecimento. Além disso, procurou-se, a partir de colocações feitas pelos respondentes, acrescentar novos tópicos relevantes que não haviam sido previstos no roteiro original. As entrevistas foram realizadas pessoalmente pelos autores do estudo entre dezembro de 2005 e janeiro de 2008, no ambiente da empresa e em escritório localizado em Porto Alegre. As entrevistas foram gravadas e, após, transcritas, de forma a possibilitar análise de conteúdo e criação de categorias de análise, no momento da descrição dos resultados. Como fontes secundárias, foram utilizados documentos internos da empresa, como relatórios e memorandos diversos, de forma a possibilitar aos pesquisadores a complementação de dados.

Como base para análise dos dados das entrevistas em profundidade realizadas foi utilizada a técnica da análise de conteúdo. Para Godoy (1995b) a análise de conteúdo é um instrumental que se presta para analisar os discursos e as diversas formas de comunicação. Uma definição da análise de conteúdo pode ser assim descrita:

\footnotetext{
${ }^{1}$ Ver maiores detalhes sobre a Rede Petro-RS em Balestro et al. (2004).
} 
Um conjunto de técnicas de análise das comunicações visando obter por procedimentos sistemáticos e objetivos de descrição do conteúdo das mensagens indicadores (quantitativos ou não) que permitam a inferência de conhecimentos relativos às condições de produção/recepção (variáveis inferidas) destas mensagens (BARDIN, 2008, p. 44).

A análise de conteúdo (content analysis) pode ser utilizada para diferentes finalidades sob diferentes formas. Por um lado, a análise de conteúdo pode ser utilizada quantitativamente. Nesse caso, o que serve como informação é a freqüência dos padrões encontrados no conteúdo analisado. Por outro lado, a análise de conteúdo também pode ser utilizada de forma qualitativa. Desse ponto de vista, esse ferramental é utilizado para identificar padrões que, surgem ou não, nos discursos e documentos analisados (VERGARA, 2007; BARDIN, 2008). Essa pesquisa se utilizará da análise qualitativa de conteúdo. Nesse sentido se procura compreender as características/padrões latentes, ou sua ausência, que estão subjacentes ao material coletado. Para além da descrição, característica inerente a análise de conteúdo, tal ferramenta permite ao analista a condição de realizar inferências (deduzir de maneira lógica) a partir do material manipulado (BARDIN, 2008). A Figura 3 apresenta o esquema geral utilizado para análise do conteúdo.

Figura 3 - Procedimentos a serem adotados na Análise de Conteúdo

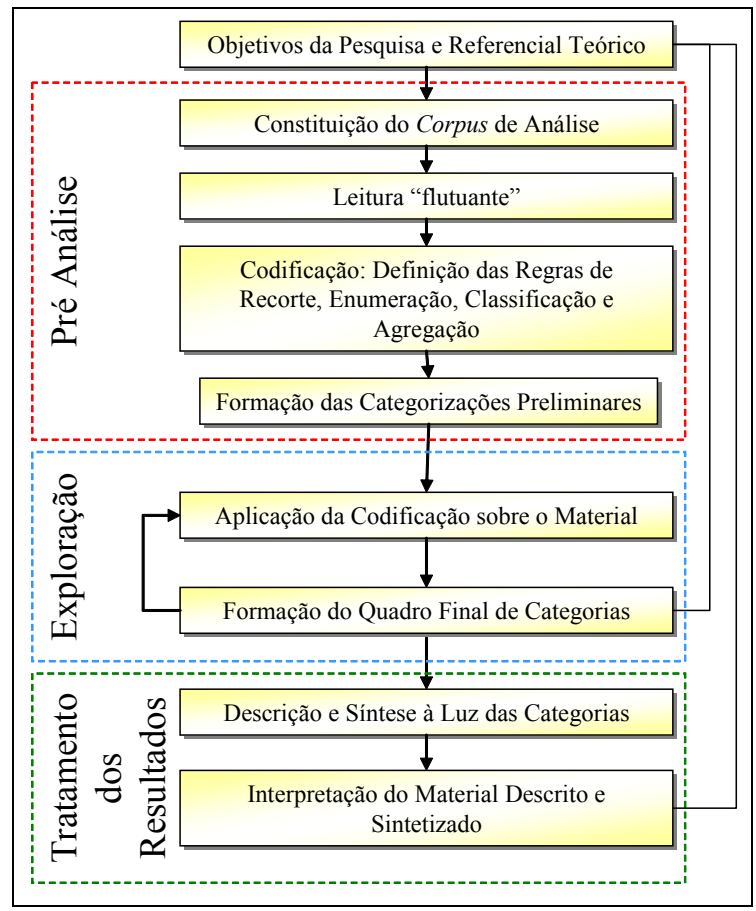

Fonte: Elaborado pelos autores. 
Nesse momento cabe a explicitação das regras que irão reger a codificação do material. Pela codificação, os dados brutos são transformados sistematicamente e agregados em unidades, visando descrever as características pertinentes ao conteúdo (BARDIN, 2008). Segundo Bardin (2008) a organização da codificação corresponde a três escolhas: (i) regras de recorte: escolha das unidades de registro e de contexto; (ii) enumeração: escolha das regras de contagem; e (iii) classificação e agregação: escolha das categorias.

A unidade de registro "é a unidade de significação a codificar e corresponde ao segmento de conteúdo a considerar com unidade de base, visando à categorização e a contagem frequencial” (BARDIN, 2008, p. 130). Bardin (2008) considera como unidades de registro a palavra, o tema, um objeto, um personagem, um acontecimento, um documento. Para os fins dessa pesquisa foi utilizado como unidade de registro o tema, ou seja, "a unidade de significação que se liberta naturalmente de um texto a ser analisado segundo certos critérios relativos à teoria que serve de guia à leitura" (BARDIN, 2008, p. 131).

A unidade de contexto serve de unidade de compreensão da unidade de registro. Corresponde ao segmento da mensagem, cujas dimensões (superiores à unidade de registro) são adequadas para compreender a unidade de registro (BARDIN, 2008). Há uma recomendação de Bardin (2008) de que se utilize como unidade de contexto a frase, quando a unidade de registro é a palavra, e o parágrafo quando a unidade de registro for o tema. Assim sendo, a unidade de contexto para essa pesquisa será o parágrafo.

Enquanto a unidade de registro diz respeito ao que se conta, a regra de enumeração informa o modo de contagem (BARDIN, 2008). Há diversas formas de se proceder a contagem: presença ou ausência, freqüência, freqüência ponderada, intensidade, direção, ordem entre outras. Para os fins desse trabalho será utilizada a freqüência. Isso deriva do postulado expresso por Bardin (2008, p. 134) de que "a importância de uma unidade de registro aumenta com a freqüência de aparição".

A etapa de categorização visa classificar os elementos constitutivos de um conjunto por diferenciação e, seguidamente, por reagrupamento segundo o gênero (analogia), com critérios previamente definidos (BARDIN, 2008). O processo de categorização prevê uma fase de isolamento e de classificação. Para os fins desse 
trabalho o critério utilizado para categorização será semântico. Segundo Bardin (2008) esse é o critério adequado quando a unidade de registro é o tema.

Por fim, para fins do processo de formação das categorias preliminares para as subseqüentes será utilizado o desenvolvimento indutivo de categorias (BARDIN, 2008; VERGARA, 2007). Vergara (2007) chama esse tipo de procedimento de grade aberta. Por esse processo identificam-se categorias de análise, conforme as mesmas vão surgindo no decorrer da pesquisa. Caso necessário, procede-se o rearranjo das categorias durante o andamento da pesquisa. Por fim, estabelecem-se as categorias de análise (VERGARA, 2007). Godoy (1995a) corrobora com esse tipo de procedimento, propondo que as questões ou focos de interesses amplos, que se tornam mais diretos e específicos ao transcorrer da investigação. Tal procedimento se alinha às características indutivas apresentadas no delineamento da pesquisa e, portanto, será o procedimento que será utilizado. Também serão obedecidos os critérios necessários para a qualidade das categorias, a saber: (i) exclusão mútua; (ii) homogeneidade; (iii) pertinência; (iv) objetividade e fidelidade; e (v) produtividade (BARDIN, 2008).

$\mathrm{Na}$ fase de exploração foram cumpridas as decisões tomadas na fase préanálise. Há, por fim, a formação do quadro final das categorias, bem como as freqüências cruzadas encontradas. Nesse momento há uma interação com o arcabouço teórico que orienta a pesquisa. Além disso, serão extraídos do corpus afirmações significantes para cada uma das categorias de forma cruzada, assim como as freqüências. Tal procedimento tem por objetivo fundamentar e ilustrar a percepção dos entrevistados em relação às categorias.

Para o tratamento dos dados foram utilizadas a síntese e a descrição, bem como a interpretação do material. Dado que "os pesquisadores qualitativos estão preocupados com o processo e não simplesmente com os resultados ou produtos" (GODOY, 1995a, p. 12), serão organizados textos descritivos a partir das categorias, utilizando-se das freqüências e das extrações de afirmação. Para o processo de descrição e síntese, conforme recomenda Yin (2005) para os estudos de caso, podem ser utilizados documentos complementares para sustentação das afirmações. Por fim, são sintetizados os principais resultados encontrados no processo de análise dos dados. Realizada a descrição da metodologia empregada 
no estudo, procede-se, a seguir, à caracterização da empresa na qual foi feita a pesquisa.

\section{CARACTERIZAÇÃO, DESCRIÇÃO, ANÁLISE E SÍNTESE DO ESTUDO DE CASO}

A seguir é apresentado o caso estudado. Inicialmente se caracteriza a organização. Análise e síntese são então apresentadas na tentativa de responder ao questionamento proposto na introdução.

\subsection{Caracterização da Empresa}

A empresa de foco do estudo ${ }^{2}$ encontra-se localizada no Estado do Rio Grande do Sul. Trata-se de uma empresa industrial de capital fechado nacional. Desde 1929 dedica-se ao estudo, pesquisa, desenvolvimento e fabricação de fios, cordas e cabos em geral. Para essa fabricação utilizavam-se fibras vegetais (cânhamo, linho, sisal e algodão) e fios metálicos (cobre e alumínio); atualmente, empregam-se exclusivamente fibras sintéticas. Instalada em uma área de $14.000 \mathrm{~m}^{2}$, com aproximadamente $9.900 \mathrm{~m}^{2}$ de área construída, mantém cerca de 190 funcionários, tendo capacidade instalada de produção de mais de 550 toneladas/mês.

O propósito da empresa é a produção de estruturas tensis com fibras sintéticas (fios, cordas e cabos) de alto desempenho para aplicações de atracação, navais, ancoragem em águas profundas, náuticas, de segurança e de uso geral. Além disso, a empresa pratica a reciclagem de cabos e fibras sintéticas de polietileno e polipropileno há um número significativo de anos. Com o aumento da demanda por cabos de poliéster de alta densidade para aplicação em ancoragem de plataformas em águas profundas, a empresa investe na pesquisa para a reciclagem de cabos desse material, a fim de recuperar as características dessas fibras para a reaplicação em cabos navais e offshore.

Os produtos da empresa estão presentes em portos de diferentes países (Holanda, Mônaco, Bélgica e EUA). Isto inclui terminais oceânicos e plataformas que

\footnotetext{
${ }^{2}$ Por solicitações dos participantes da pesquisa o nome da empresa, em tela, foi omitido.
} 
operam no Mar do Norte, no México, na Índia, no Golfo Pérsico, no Extremo Oriente e, principalmente, na América do Sul (Brasil, Argentina e Chile, entre outros), sendo reconhecido como um dos principais fornecedores de cordas e cabos para esses mercados. A empresa possui em média $15 \%$ do mercado nacional, que é estimado em R $\$ 150$ milhões ao ano, e 3\% do mercado internacional, estimado atualmente, conforme a empresa, em $\mathrm{R} \$ 2$ bilhões ao ano.

Desde 1974, a empresa se desenenvolve em ações inovadoras, principalmente no desenvolvimento de produtos e máquinas para fabricação e ensaios de cabos sintéticos, mantendo-se, desde essa época, atualizada tecnologicamente em relação aos líderes mundiais na fabricação de seus produtos.

A seguir, alguns eventos (de 1986 a 1995) serão aprofundados, enfatizando o tipo de inovação, o grau de inovação, o tipo de aprendizagem organizacional utilizada para a inovação e o processo de aprendizagem organizacional existente em cada evento.

\subsection{Descrição do Caso}

O caso da empresa, foco do estudo, será analisado de acordo com uma linha de tempo que compreende diversas situações de inovação e aprendizagem ocorridas no período de 1986 a 1995. Após isso, cada período será analisado individualmente, de maneira a formar uma visão geral dos processos de inovação e aprendizagem.

\section{a) A Segunda Metade da Década de 1980 (1986 a 1989) - Começando a Inovar}

Na metade da década de 1980, a empresa enfrentava um problema de falta de capacidade de produção frente à demanda existente. Nesse período, a empresa contrata um diretor industrial para solucionar essa situação, que decide iniciar a ampliação da capacidade de produção através do aumento no número de máquinas de fabricação de cabos. No entanto, ao invés de importá-las, a decisão foi efetuar uma engenharia reversa, com base nas máquinas importadas da Alemanha no início da década de 1980 (utilizadas na fabricação de cabos trançados de 8 pernas para a amarração de navios em portos), e produzir as novas máquinas no próprio ambiente 
industrial da empresa, com auxílio de linhas de financiamento do governo federal.

Além disso, neste mesmo período, o diretor industrial teve a idéia de desenvolver o cabo trançado de 12 pernas, um produto novo no país, com maior tenacidade, maior firmeza e menor abrasão do que o cabo trançado de 8 pernas até então existente. A idéia visava atender uma demanda do seu maior cliente, a Petrobras (empresa de capital nacional de exploração de petróleo e derivados). No entanto, para desenvolver este produto, exigiu-se o desenvolvimento de novo maquinário para o processo produtivo, visto que as existentes na empresa não seriam capazes de produzir tal produto. Então, a máquina trançadeira de 12 pernas, que inexistia no mundo, foi desenvolvida ao longo de dois anos. Durante todo o processo, reuniões eram realizadas entre representantes da empresa e da cliente demandante, com vistas a acompanhamento do processo e esclarecimento de eventuais dúvidas.

Porém, quando faltava cerca de um mês para a conclusão da máquina, o principal fabricante de cabos da época, a Hextron (empresa norte-americana), lançou no mercado um cabo redondo de 12 pernas. Este fato, apesar de ter causado um impacto negativo dentro da empresa (pois nenhuma das empresas concorrentes sabia de seus desenvolvimentos em paralelo), motivou a empresa a desenvolver os seus produtos e processos em um menor lead-time (tempo de atravessamento). $\mathrm{O}$ lançamento inicial do cabo trançado de 12 pernas no mercado foi difícil porque já existia entre os clientes uma cultura no uso dos cabos trançados de 8 pernas. No entanto, depois que se verificou que o cabo trançado de 12 pernas apresentava uma qualidade superior, o produto apresentou uma boa aceitação pelo mercado.

No final da década de 1980, a Petrobras solicitou à empresa o desenvolvimento de um cabo de dupla trança de 12 pernas, que importava na época da Hextron. Para fabricar tal cabo, que era novo no mercado nacional, seria outra vez necessário desenvolver novas máquinas. Então o diretor industrial da empresa projetou uma máquina de 32 pernas, esta de caráter inovador em âmbito mundial. $A$ Petrobras, para comprar esse cabo, requereu testes de resistência. Novamente a empresa foco do estudo decidiu desenvolver internamente seus próprios equipamentos de ensaio, o que se tratava de um grande desafio, dado o contexto técnico da época. 


\section{b) A Primeira Metade da Década de 1990 (1990 a 1995) - A Criação de Parcerias Inovadoras}

No início da década de 1990, o cenário na indústria petrolífera mundial acenava para o desenvolvimento de novos sistemas de ancoragem para águas ultraprofundas, sendo demandados, no Brasil, principalmente pela Petrobras. Até este período, a Petrobras vinha utilizando tradicionalmente amarras de aço, cabos de aço e lâminas d'água de 1.500 metros. Foi então que a empresa foco foi convidada pela Petrobras para desenvolver um cabo de poliéster com capacidade para 500 toneladas de ruptura, justamente para o segmento de ancoragem em águas ultraprofundas. $\mathrm{O}$ convite surgiu em um treinamento que a empresa oferece anualmente sobre seus produtos aos principais clientes, fornecedores e centros de pesquisa por meio de um técnico da Petrobras que estava fazendo esse curso e havia realizado o doutorado na Inglaterra sobre sistemas de ancoragem alternativos a partir de fibras sintéticas. A partir deste momento, a empresa começou a desenvolver o produto em parceria com a Petrobras, enviando protótipos para avaliação deste cliente e posteriormente realizando diversas reuniões formais para alinhamento do projeto. No entanto, para fornecer o produto, necessitava-se de matéria-prima adequada às exigências da Petrobras, o que demandou o desenvolvimento de um novo fornecedor de fibras de poliéster capaz de apoiar este projeto. Durante o desenvolvimento deste fornecedor, diversas visitas técnicas foram realizadas por representantes da empresa foco à seu novo fornecedor.

Além disso, uma série de testes foi necessária para os quais não se possuía equipamento disponível e apto no país à época. Na época, existiam dois centros de pesquisa no mundo capazes de efetuar tais ensaios, localizados na Escócia e na Dinamarca, que eram acessíveis aos principais concorrentes da empresa. Então, foi tomada a decisão de, novamente, desenvolver os equipamentos necessários para a execução dos testes. Neste caso, os equipamentos de testes já existentes sofreram adaptações, principalmente em peças forjadas, com o auxílio de uma empresa especializada neste tipo de material, a fim de se enquadrarem às exigências feitas pela Petrobras. O equipamento de ensaio passou a ter condições de testar até 500 toneladas de cabo, fato que a diferenciava perante os concorrentes, pois ainda continuavam dependentes dos dois centros de pesquisa citados anteriormente. 
Nesta ocasião, os procedimentos para registro do desenvolvimento em suas diversas etapas eram feitos em relatórios impressos, sendo os principais a ordem de produção, o relatório de testes e o relatório dimensional, que seguiam o mesmo padrão dos procedimentos dos produtos anteriores. Porém, outras exigências se fizeram necessárias, como o desenvolvimento dos manuais de utilização do usuário em língua inglesa, até então inéditos na empresa e relevantes para o projeto de internacionalização da empresa, além do procedimento administrativo de registro e documentação se tornar rigoroso em função das exigências impostas pela empresa demandante.

Em 1995, como a demanda por cabos de dupla trança para ancoragem em águas profundas continuava crescendo, a empresa efetivou, junto à Petrobras, um acordo de cooperação para o desenvolvimento de um sistema de ancoragem para ser aplicado em uma plataforma petrolífera (P13) no valor de US\$ 1 milhão. Neste acordo de cooperação ocorreu uma antecipação de recursos financeiros da Petrobras com o objetivo de investir em alterações no equipamento de testes já existente e no produto para tal plataforma. Este acordo de cooperação durou cerca de um ano. Esse tempo era suficiente para o desenvolvimento das alterações na máquina de ensaio e para o desenvolvimento do produto em si. Durante este período, imprevistos ocorreram: (i) constantes mudanças no projeto do produto se fizeram necessárias, pois era preciso adequar-se ao desempenho desejado pela Petrobras; (ii) como não existia fornecedor no país da matéria-prima necessária à fabricação do produto especificado e a importação da mesma possuía um lead-time elevado, decidiu-se desenvolver junto à empresa Fiber (fornecedor de fibras) uma fibra sintética que atendesse às especificações; (iii) durante os testes do produto no equipamento de ensaio, foram necessárias adaptações ao tamanho, à carga de peso (que era de 525 toneladas) e à carga de ruptura (que era de 493 toneladasforça) do cabo a ser entregue. Ao final, o projeto foi finalizado e homologado, mas o cabo não foi utilizado para a sustentação da plataforma, mas para ancoragem de monobóias (esta decisão de mudança na utilização do produto ocorreu por parte da Petrobras); e; (iv) adaptações nas máquinas de fabricação do novo cabo. 


\subsection{Análise das Situações de Inovação e Aprendizagem}

Uma vez realizadas as descrições das situações de inovação e aprendizagem no período de tempo compreendido entre 1986 e 1995, passa-se, neste momento, à análise de cada uma delas de acordo com esses mesmos períodos.

\section{a) As Inovações e Aprendizagens na Segunda Metade da Década de 1980 (1986 a 1989)}

Neste período pode-se afirmar que diversas inovações ocorreram em paralelo. A primeira é a inovação radical em gestão, pois a empresa foco deixou de importar e comprar prontas as máquinas e equipamentos que eram necessários ao seu negócio para desenvolvê-los internamente. Isso implica em uma mudança na estratégia de Pesquisa e Desenvolvimento (P\&D), que passou da horizontalização para a verticalização, algo inédito mundialmente neste setor. No desenvolvimento do cabo trançado de 12 pernas, pode-se afirmar que o mesmo tratou-se de uma inovação de produto incremental em nível mundial, pois já existia nos EUA e na Europa. Além disso, verifica-se neste projeto, uma inovação de processo radical, uma vez que a máquina trançadeira de 12 pernas desenvolvida pela empresa para a fabricação deste cabo não existia no mundo. Este fato também acabou influenciando na inovação de mercado, que neste caso acabou sendo incremental em nível mundial, pois as empresas européias que possuíam este produto já tinham iniciado o processo de abertura e expansão deste mercado específico de cabos de ancoragem.

No que tange aos tipos de aprendizagem identificados em cada inovação, também podem ser identificados diversos tipos existentes neste período. $\mathrm{Na}$ inovação de gestão, pode-se identificar a aprendizagem por pesquisa (a empresa teve que pesquisar através da engenharia reversa a partir de outras máquinas, como iria fabricar a máquina trançadeira de 12 pernas). Quando a empresa precisou se integrar junto à Petrobras para desenvolver o projeto do cabo trançado de 12 pernas identifica-se uma aprendizagem por interação. Quanto à inovação de mercado, o tipo de aprendizagem identificada é a de pesquisa (a empresa teve que entender como este mercado estava operando e quais suas principais características). No que 
tange à inovação no processo, verificam-se principalmente as aprendizagens por fazer (pois os componentes e peças da máquina estavam sendo feitas internamente), por usar (pois à medida que o processo foi sendo desenvolvido identificaram-se problemas que eram ajustados a partir da utilização do processo) e por pesquisa (pois o departamento de P\&D da empresa teve que efetuar diversas modificações de projeto para atender a viabilidade técnico-econômico e, por conseguinte, as exigências do cliente).

Já no caso do projeto do cabo de dupla trança de 12 pernas que a empresa desenvolveu para a Petrobras, fica evidente. A busca de inovações essenciais para alavancar a competitividade da empresa. Quanto ao produto, verifica-se novamente uma inovação de produto incremental, visto que este produto já existia no mundo. Além disto, este projeto apresenta uma inovação radical de processo, identificada na construção da máquina trançadeira de 32 pernas, utilizada para a fabricação do produto, que era única no mundo. Também, apresenta uma inovação incremental de processo, em nível mundial, quando resolve desenvolver seus próprios equipamentos de ensaio, pois os mesmos já existiam em centros de pesquisa europeus. E por último, pode-se identificar que existiu uma inovação incremental de mercado para a empresa, que até então não atuava com cabos de dupla trança, mas este mercado já tinha sido desenvolvido por empresas européias do segmento.

Do ponto de vista da aprendizagem, identifica-se em cada uma das principais inovações algum tipo de aprendizagem específica neste projeto do cabo de dupla trança de 12 pernas. No caso da inovação do produto, aparece com destaque a aprendizagem por interação (uma vez que a Petrobras foi quem demandou o desenvolvimento do produto à empresa foco). Na inovação radical de processo, identificam-se: i) as aprendizagens por uso (pois à medida que a máquina trançadeira de 32 pernas era desenvolvida, ajustes eram feitos para a obtenção do desempenho desejado); ii) por fazer (diversos componentes e peças desta máquina necessitaram ser refeitos no setor de matrizaria da empresa, em função de erros de projeto) e; iii) por pesquisa (como o grau de complexidade técnica do projeto era elevado, o departamento de P\&D da empresa ficou focado exclusivamente no mesmo, a fim de superar todas as dificuldades que fossem surgindo). Esta inovação radical de processo foi essencial do prisma da competitividade dada à dificuldade de cópia inerente a este tipo de inovação. 
Já quanto à inovação incremental de processo, é possível identificar: i) aprendizagens por uso (pois pequenos ajustes eram feitos no equipamento de ensaio existente na empresa); ii) por fazer (como existia um setor de matrizaria na empresa, alguns componentes e peças necessários ao equipamento de ensaio eram feitos com as devidas alterações) e; iii) por pesquisa (pois o departamento de P\&D da empresa apoiava-se no fornecimento de informações sobre os melhores materiais a serem utilizados para a fabricação de tal equipamento). E quanto à inovação em mercado, pode-se dizer que apresenta preponderantemente a aprendizagem por pesquisa (pois demandava o conhecimento das características e perfil do mercado consumidor de cabos de dupla trança).

De outro ponto de vista, a decisão de desenvolver internamente o produto, ao invés de adquiri-lo no mercado internacional, constituiu-se numa aprendizagem double loop, pois tratou-se de uma mudança estratégica da empresa a partir da aposta em sua expertise interna. Com isso, houve mudança nos princípios que até então regiam a atuação da empresa. Quanto ao desenvolvimento do cabo trançado de 12 pernas, também pode ser caracterizada como uma forma de aprendizagem de ciclo duplo, pois envolveu mudança numa orientação até então existente (aquisição no exterior) e demandou uma série de implementações em processos para viabilizar essa nova diretriz, gerando resultados positivos e, até mesmo, impactando no mercado, pois não havia esse produto no Brasil.

Observou-se ainda a ocorrência de todas as quatro formas de conversão de conhecimento. Internalização, pois foi realizada a análise do produto, por meio de engenharia reversa, que já existia no mercado internacional, para seu desenvolvimento no Brasil (ou seja, partiu-se de um conhecimento explícito para transformá-lo em conhecimento tácito); socialização, visto que a aprendizagem gerada por parte dos técnicos e engenheiros no desenvolvimento do produto foi absorvida pelos mesmos e passou a fazer parte de seus arcabouços pessoais (conhecimento tácito em tácito); combinação, uma vez que os conhecimentos que havia em relação às formas de produção até então existentes e adquiridas através da engenharia reversa foram explícitas e convertidas em formas de conhecimento igualmente explícito, naqueles procedimentos que ficaram abertos e de conhecimento de todos os participantes do processo; e externalização, pois uma parte dos conhecimentos adquiridos pela empresa no desenvolvimento do produto 
acabou sendo, depois, decodificada e transformada em normas internas de ação (conversão de conhecimento tácito em explícito).

Quanto aos espaços de criação do conhecimento, nessa época, na empresa, ainda não se utilizava internet como meio de interação. Outros meios de comunicação que prescindem de contato face a face, como telefone, também não eram adequados a um processo de tamanha complexidade, como desenvolvimento de um produto inovador. Assim, para essa situação, houve a ocorrência de originating ba e dialoguing ba, pois os contatos entre os técnicos da empresa demandante e da Cabos \& Cordas ocorreram em situações específicas, nas quais um especialista visitava a planta da empresa, fazia os testes necessários e trocava informações, individualmente (ou seja, espaço de interação individual e face a face). Além disso, houve o dialoguing ba, pois houve momentos de reuniões entre participantes do projeto das duas empresas e explanações orais para grupos de técnicos, representando espaço coletivo e face a face de interação.

\section{b) As Inovações e Aprendizagens na Primeira Metade da Década de 1990 (1990 a 1995)}

O projeto do cabo de poliéster de 500 toneladas apresentou diversas inovações ao mesmo tempo. Quanto ao produto, pode-se dizer que ocorreu uma inovação incremental em nível mundial, pois este cabo já existia na Europa. O projeto também apresentou uma inovação de mercado radical para a empresa foco, pois a mesma acabou capacitando-se a entrar no novo mercado de cabos de ancoragem em águas ultra-profundas, que era novo para a própria Petrobras. Quanto ao processo produtivo deste produto, pode-se afirmar que a inovação, incluindo a etapa de testes e ensaios, foi incremental, pois necessitou de algumas adaptações nas máquinas e equipamentos já existentes. Outra inovação ocorrida neste projeto foi quanto à matéria-prima, observada como radical, pois a empresa necessitou desenvolver uma nova fibra de poliéster junto a um fornecedor, matériaprima até então inexistente no mercado mundial. E ocorreu uma inovação incremental na gestão dos procedimentos e registros do produto e processo, onde foram melhorados os padrões de relatórios e documentos, pois eram entregues para avaliação da Petrobras. 
Quanto aos tipos de aprendizagem identificados em cada inovação, podem ser identificados diversos ocorrendo neste projeto. Quanto à integração da empresa à Petrobras para desenvolver o produto, identifica-se uma aprendizagem por interação. Quanto à inovação de mercado, o tipo de aprendizagem identificada é a de pesquisa, pois a empresa foco necessitou entender como este mercado, que era novo e que estava em expansão, estava operando e quais eram suas principais características. No que tange às inovações no processo, tanto nas máquinas utilizadas na fabricação do produto quanto no equipamento de ensaio utilizado para os testes, verifica-se: i) aprendizagens por fazer (a própria empresa aprendia com a adaptação das peças e componentes utilizados nas máquinas e equipamentos existentes); ii) por uso (pois pequenos ajustes eram feitos no equipamento de ensaio e nas máquinas de fabricação já instaladas) e; iii) por pesquisa (o departamento de P\&D da empresa apoiou principalmente a solução de um problema no sistema de amarra do cabo).

Quanto às inovações de matéria-prima, verifica-se aprendizagens por pesquisa (a empresa teve que procurar qual seria o melhor fornecedor para atender a sua demanda), por interação (pois a empresa teve que se relacionar com os fornecedores de fibra de poliéster e de peças forjadas) e por uso (quando a empresa utilizava as novas fibras sintéticas fornecidas, avaliava os parâmetros e controlava os mesmos até o momento em que atingissem as características desejadas). E a inovação na gestão caracterizou-se principalmente pelas aprendizagens por uso e por fazer, em que se verificou que seria importante, para a memória da empresa e ao atendimento de todas as exigências do cliente, um sistema de registro e controle mais rígido e formalizado dos principais eventos na matéria-prima, noss equipamentos e máquinas, e no produto final.

Já no caso do projeto do sistema de ancoragem da plataforma P13, é possível destacar um conjunto de inovações que ocorreram simultaneamente. Quanto ao produto, pode-se dizer que ocorreu uma inovação radical em nível mundial, pois este cabo não existia até então. O projeto também representou uma inovação de mercado incremental para a empresa, pois a mesma já estava atuando no segmento de cabos para aplicações em águas ultra-profundas. Quanto às inovações de processo, incluindo as máquinas de fabricação e o equipamento de ensaio, é possível classificar as mesmas como de caráter incremental, pois exigiram 
adaptações em recursos que já existiam na empresa. E ocorreu uma inovação radical na matéria-prima, pois a empresa teve que desenvolver uma nova fibra de poliéster, que não existia no mercado mundial, junto à fornecedora Fiber.

No que tange aos tipos de aprendizagem existentes no projeto do sistema de ancoragem da plataforma $\mathrm{P} 13$, pode-se salientar a diversidade e a ocorrência simultânea dos mesmos. Na inovação do produto, verifica-se claramente uma aprendizagem por interação, pois a mesma parte de uma demanda da Petrobras na qual são realizados encontros para a discussão do projeto. Quanto à inovação de mercado, o tipo de aprendizagem identificada é a de pesquisa, pois a empresa foco teve apenas que acompanhar as tendências e exigências de um mercado já existente.

No que tange às inovações no processo, tanto nas máquinas utilizadas na fabricação do produto quanto no equipamento de ensaio utilizado para os testes, foi possível observar: i) as aprendizagens por fazer (a própria empresa aprendia com a adaptação das peças e componentes utilizados nas máquinas e equipamentos existentes); ii) por uso (pois pequenos ajustes eram feitos no equipamento de ensaio e nas máquinas de fabricação já instaladas) e; iii) por pesquisa (o departamento de P\&D da empresa auxiliava na solução de problemas que fossem surgindo no projeto). E nas inovações de matéria-prima, verificam-se as aprendizagens por pesquisa (a empresa teve que procurar qual seria o melhor fornecedor para atender a sua demanda), por interação (pois a empresa teve que se relacionar com a fornecedora Fiber para desenvolver tal material) e por uso (quando a empresa utilizava as novas fibras sintéticas fornecidas, avaliava os parâmetros e controlava os mesmos até o momento em que atingissem as características desejadas). No entanto, verifica-se que para a geração dessas inovações a organização em estudo não realizou o pedido de patentes para as mesmas, o que mostra que nesse período a empresa não valorizava esse importante mecanismo de garantia da propriedade e autoria de desenvolvimento das inovações. Em levantamento de informações mais recentes (a partir de 2000) junto à alguns executivos da empresa, foi informado que a mesma passou a solicitar registro de patentes para inovações tecnológicas (produto e produto) desenvolvidas de forma sistematizada, pois implantou uma política de inovação em que a proteção das inovações é pressuposto básico. 
Já conforme as linhas de aprendizagem organizacional selecionadas para este caso, o projeto do cabo de poliéster de 500 toneladas envolve aprendizagem do tipo single loop, uma vez que foram realizadas adaptações em processos já existentes, sem implicar mudanças nos princípios ou normas da empresa. $\mathrm{O}$ uso de fibras de poliéster representa uma aprendizagem double loop, pois acabou gerando uma mudança expressiva na forma de produção dos cabos, a partir de então, ocasionando alterações na própria estratégia de atuação da empresa. Quanto à gestão de procedimentos, com a necessidade de sistematização inerente a esse processo, trata-se de uma aprendizagem por ciclo simples, tendo em vista que se modificou uma ação, sem afetar significativamente os resultados, mas sim melhorando a forma de registros, classificação e sistematização de procedimentos.

Quanto às formas de conversão de conhecimento, pode ser identificado, no caso relatado, a externalização. Isto porque houve essa sistematização de conhecimentos, com padronização e explicitação do que foi aprendido no desenvolvimento da nova fibra (conhecimento tácito em explícito), a combinação, tendo em vista que os procedimentos explícitos de produção (seja no caso do cabo de poliéster ou no do sistema de ancoragem) permaneceram desta forma, e a socialização, uma vez que a forma de desenvolvimento e o conteúdo do que foi desenvolvido foi aprendido, de forma internalizada, pelos participantes do processo (ou seja, conhecimento tácito em tácito). A internalização, que havia ocorrido nos acontecimentos do período anterior, não se verificou, a partir da análise das entrevistas, uma vez que já havia domínio do know-how por parte dos técnicos e engenheiros da empresa - ao contrário das situações vividas anteriormente.

Em relação aos espaços de criação do conhecimento, mesmo já havendo uso de Internet nessa época, esta não foi utilizada para as situações descritas. A partir do relato do funcionário do segmento tático, foi informado que houve uso de fax para troca de informações e complementação de detalhamentos técnicos - ou seja, ocorreu o exercising ba (espaço virtual e individual). Ao mesmo tempo, também se percebeu a existência de espaços do originating (individual e face a face), em situações nas quais havia visitas técnicas (para testagem e pontos de controle) à empresa por parte da demandante, e dialoguing ba, em eventos nos quais realizavam-se reuniões entre representantes das duas empresas (espaço de interação coletivo e face a face). 


\section{SÍNTESE DO CASO POR TIPO DE INOVAÇÃO}

Atualmente, a empresa ocupa uma posição de destaque e liderança internacional no segmento de sistemas de ancoragem, principalmente no mercado de águas ultra-profundas, fato que se deve principalmente às sucessivas decisões por inovar, quer seja em produto, processo, material, mercado e até mesmo na sua gestão. Durante o período de 10 anos considerado para esta pesquisa, pode-se dizer que a empresa passou por diversos ciclos de aprendizagem organizacional que proporcionaram a ela condições de se capacitar em um segmento que demanda constante atualização tecnológica, bem como de corrigir os erros ocorridos no passado. Diante do apresentado no item anterior, o Quadro 5 sintetiza, por período, qual o tipo de inovação, o grau da inovação, o tipo de aprendizagem e o processo de aprendizagem necessário em cada um dos eventos.

Quadro 5 - As inovações e aprendizagens da empresa foco, de 1986 a 1995

\begin{tabular}{|c|c|c|c|c|c|c|c|}
\hline \multirow[b]{2}{*}{ Projeto } & \multirow[b]{2}{*}{$\begin{array}{l}\frac{0}{0} \\
\frac{0}{0} \\
0\end{array}$} & \multirow[b]{2}{*}{$\begin{array}{l}\text { Tipo de } \\
\text { Inovação }\end{array}$} & \multirow[b]{2}{*}{$\begin{array}{l}\text { Grau de } \\
\text { Inovação }\end{array}$} & \multirow[b]{2}{*}{$\begin{array}{c}\text { Tipo de } \\
\text { Aprendizage } \\
\text { m } \\
\text { (MALERBA, } \\
\text { 1992) }\end{array}$} & \multicolumn{3}{|c|}{ Processo de Aprendizagem } \\
\hline & & & & & 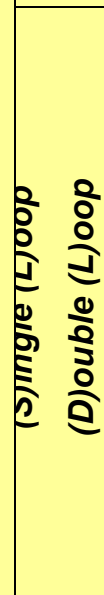 & $\begin{array}{c}\text { Forma de } \\
\text { conversão do } \\
\text { conheciment } \\
\text { o } \\
\text { (S)ocialização } \\
\text { (E)xternalizaç } \\
\text { ão } \\
\text { (C)ombinação } \\
\text { (I)nternalizaç } \\
\text { ão }\end{array}$ & $\begin{array}{c}\text { Espaço de } \\
\text { interação } \\
\text { (O)origina } \\
\text { ndo } \\
\text { (D)ialogan } \\
\text { do } \\
\text { (E)xercitan } \\
\text { do }\end{array}$ \\
\hline $\begin{array}{l}\text { Nacionaliza } \\
\text { ção própria } \\
\text { de } \\
\text { máquinas } \\
\text { de } \\
\text { fabricação } \\
\text { de cabos }\end{array}$ & $\begin{array}{c}1986 \\
- \\
1987\end{array}$ & Gestão & Radical & Por pesquisa & CD & S, I & $\mathrm{O}, \mathrm{D}$ \\
\hline $\begin{array}{c}\text { Cabo } \\
\text { trançado de }\end{array}$ & $\begin{array}{c}1986 \\
-\end{array}$ & Produto & $\begin{array}{c}\text { Increment } \\
\text { al }\end{array}$ & Por interação & CS & $E, C$ & O, D \\
\hline 12 pernas e & 1987 & Processo & Radical & Pelo fazer & CD & S, I & $O, D$ \\
\hline
\end{tabular}




\begin{tabular}{|c|c|c|c|c|c|c|c|}
\hline \multirow[b]{2}{*}{ Projeto } & \multirow{5}{*}{$\frac{}{\frac{0}{0}}$} & \multirow[b]{2}{*}{$\begin{array}{l}\text { Tipo de } \\
\text { Inovação }\end{array}$} & \multirow[b]{2}{*}{$\begin{array}{l}\text { Grau de } \\
\text { Inovação }\end{array}$} & \multirow[b]{2}{*}{$\begin{array}{c}\text { Tipo de } \\
\text { Aprendizage } \\
\text { m } \\
\text { (MALERBA, } \\
\text { 1992) }\end{array}$} & \multicolumn{3}{|c|}{ Processo de Aprendizagem } \\
\hline & & & & & 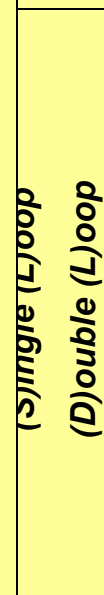 & $\begin{array}{c}\text { Forma de } \\
\text { conversão do } \\
\text { conheciment } \\
\text { o } \\
\text { (S)ocialização } \\
\text { (E)xternalizaç } \\
\text { ão } \\
\text { (C)ombinação } \\
\text { (I)nternalizaç } \\
\text { ão }\end{array}$ & $\begin{array}{c}\text { Espaço de } \\
\text { interação } \\
\text { (O)origina } \\
\text { ndo } \\
\text { (D)ialogan } \\
\text { do } \\
\text { (E)xercitan } \\
\text { do }\end{array}$ \\
\hline \multirow{3}{*}{$\begin{array}{c}\text { máquina } \\
\text { trançadeira } \\
\text { de } 12 \\
\text { pernas }\end{array}$} & & $\begin{array}{l}\text { (máquina } \\
\text { trançadeira) }\end{array}$ & & $\begin{array}{c}\text { Por uso } \\
\text { Por pesquisa }\end{array}$ & & & \\
\hline & & $\begin{array}{c}\text { Processo } \\
\text { (equipamen } \\
\text { to de } \\
\text { ensaio) }\end{array}$ & $\begin{array}{c}\text { Increment } \\
\text { al }\end{array}$ & $\begin{array}{c}\text { Pelo fazer } \\
\text { Por uso } \\
\text { Por pesquisa }\end{array}$ & CS & $E, C$ & O, D \\
\hline & & Mercado & $\begin{array}{c}\text { Increment } \\
\text { al }\end{array}$ & Por pesquisa & CS & $E, C$ & O, D \\
\hline \multirow{4}{*}{$\begin{array}{c}\text { Cabo de } \\
\text { dupla trança } \\
\text { de } 12 \\
\text { pernas e } \\
\text { máquina } \\
\text { trançadeira } \\
\text { de } 32 \\
\text { pernas }\end{array}$} & \multirow{4}{*}{$\begin{array}{c}1988 \\
- \\
1989\end{array}$} & Produto & $\begin{array}{c}\text { Increment } \\
\text { al }\end{array}$ & Por interação & CS & $E, C$ & O, D \\
\hline & & $\begin{array}{l}\text { Processo } \\
\text { (máquina } \\
\text { trançadeira) }\end{array}$ & Radical & $\begin{array}{c}\text { Pelo fazer } \\
\text { Por uso } \\
\text { Por pesquisa }\end{array}$ & CD & I, S, & O, D \\
\hline & & $\begin{array}{c}\text { Processo } \\
\text { (equipamen } \\
\text { to de } \\
\text { ensaio) }\end{array}$ & $\begin{array}{c}\text { Increment } \\
\text { al }\end{array}$ & $\begin{array}{c}\text { Pelo fazer } \\
\text { Por uso } \\
\text { Por pesquisa }\end{array}$ & CS & $E, C$ & O, D \\
\hline & & Mercado & $\begin{array}{c}\text { Increment } \\
\text { al }\end{array}$ & Por pesquisa & CS & $E, C$ & O, D \\
\hline \multirow{3}{*}{$\begin{array}{l}\text { Cabo de } \\
\text { poliéster de } \\
500 \\
\text { toneladas e } \\
\text { equipament } \\
\text { o de } \\
\text { ensaios }\end{array}$} & \multirow{3}{*}{$\begin{array}{c}1993 \\
- \\
1994\end{array}$} & $\begin{array}{c}\text { Matéria- } \\
\text { prima }\end{array}$ & Radical & $\begin{array}{l}\text { Por interação } \\
\text { Por uso } \\
\text { Por pesquisa }\end{array}$ & $C D$ & $\mathrm{~S}$ & $\mathrm{O}, \mathrm{D}, \mathrm{E}$ \\
\hline & & $\begin{array}{l}\text { Processo } \\
\text { (máquina } \\
\text { trançadeira) }\end{array}$ & $\begin{array}{c}\text { Increment } \\
\text { al }\end{array}$ & $\begin{array}{c}\text { Pelo fazer } \\
\text { Por uso } \\
\text { Por pesquisa }\end{array}$ & CS & $E, C$ & O, D, E \\
\hline & & $\begin{array}{l}\text { Processo } \\
\text { (equipamen } \\
\text { to de }\end{array}$ & $\begin{array}{c}\text { Increment } \\
\text { al }\end{array}$ & $\begin{array}{c}\text { Pelo fazer } \\
\text { Por uso } \\
\text { Por pesquisa }\end{array}$ & CS & $E, C$ & $\mathrm{O}, \mathrm{D}, \mathrm{E}$ \\
\hline
\end{tabular}




\begin{tabular}{|c|c|c|c|c|c|c|c|}
\hline \multirow{6}{*}{ Projeto } & \multirow{6}{*}{$\frac{\circ}{\frac{0}{0}}$} & & & & \multicolumn{3}{|c|}{ Processo de Aprendizagem } \\
\hline & & $\begin{array}{l}\text { Tipo de } \\
\text { Inovação }\end{array}$ & $\begin{array}{l}\text { Grau de } \\
\text { Inovação }\end{array}$ & $\begin{array}{c}\text { Tipo de } \\
\text { Aprendizage } \\
\text { m } \\
\text { (MALERBA, } \\
\text { 1992) }\end{array}$ & 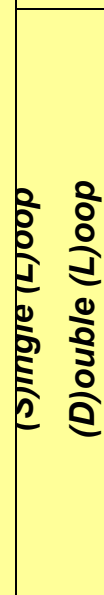 & $\begin{array}{c}\text { Forma de } \\
\text { conversão do } \\
\text { conheciment } \\
\text { o } \\
\text { (S)ocialização } \\
\text { (E)xternalizaç } \\
\text { ão } \\
\text { (C)ombinação } \\
\text { (I)nternalizaç } \\
\text { ão }\end{array}$ & $\begin{array}{c}\text { Espaço de } \\
\text { interação } \\
\text { (O)origina } \\
\text { ndo } \\
\text { (D)ialogan } \\
\text { do } \\
\text { (E)xercitan } \\
\text { do }\end{array}$ \\
\hline & & ensaio) & & & & & \\
\hline & & Produto & $\begin{array}{c}\text { Increment } \\
\text { al }\end{array}$ & Por interação & CS & $\mathrm{E}, \mathrm{C}$ & $\mathrm{O}, \mathrm{D}, \mathrm{E}$ \\
\hline & & Mercado & Radical & Por pesquisa & CD & $\mathrm{S}$, & $\mathrm{O}, \mathrm{D}, \mathrm{E}$ \\
\hline & & Gestão & $\begin{array}{c}\text { Increment } \\
\text { al }\end{array}$ & $\begin{array}{c}\text { Por uso } \\
\text { Pelo fazer }\end{array}$ & CS & $\mathrm{E}, \mathrm{C}$ & $\mathrm{O}, \mathrm{D}, \mathrm{E}$ \\
\hline \multirow{5}{*}{$\begin{array}{c}\text { Sistema de } \\
\text { ancoragem } \\
\text { da } \\
\text { plataforma } \\
\text { P13 }\end{array}$} & \multirow{5}{*}{1995} & $\begin{array}{c}\text { Matéria- } \\
\text { prima }\end{array}$ & Radical & $\begin{array}{c}\text { Por interação } \\
\text { Por uso } \\
\text { Por pesquisa }\end{array}$ & CD & $S$ & $\mathrm{O}, \mathrm{D}, \mathrm{E}$ \\
\hline & & $\begin{array}{l}\text { Processo } \\
\text { (máquina } \\
\text { trançadeira) }\end{array}$ & $\begin{array}{c}\text { Increment } \\
\text { al }\end{array}$ & $\begin{array}{c}\text { Pelo fazer } \\
\text { Por uso } \\
\text { Por pesquisa }\end{array}$ & CS & $\mathrm{E}, \mathrm{C}$ & $\mathrm{O}, \mathrm{D}, \mathrm{E}$ \\
\hline & & $\begin{array}{c}\text { Processo } \\
\text { (equipamen } \\
\text { to de } \\
\text { ensaio) }\end{array}$ & $\begin{array}{l}\text { Increment } \\
\text { al }\end{array}$ & $\begin{array}{c}\text { Pelo fazer } \\
\text { Por uso } \\
\text { Por pesquisa }\end{array}$ & CS & $E, C$ & $\mathrm{O}, \mathrm{D}, \mathrm{E}$ \\
\hline & & Produto & Radical & Por interação & CD & S & $\mathrm{O}, \mathrm{D}, \mathrm{E}$ \\
\hline & & Mercado & $\begin{array}{c}\text { Increment } \\
\text { al }\end{array}$ & Por pesquisa & CS & $\mathrm{E}, \mathrm{C}$ & $O, D, E$ \\
\hline
\end{tabular}

Fonte: Elaborado pelos autores

Conclui-se que ocorreram, no período pesquisado, duas inovações de gestão, sendo uma radical (1986-1987) e outra incremental (1993-1994). Na primeira, o tipo de aprendizagem existente foi por pesquisa e na segunda ocorreram as aprendizagens por uso e pelo fazer. O processo de aprendizagem, na inovação radical, foi de double loop, com formas de conversão do conhecimento do tipo internalização e socialização e espaços originating e dialoguing. $\mathrm{Na}$ incremental, 
houve ocorrência de single loop, externalização e combinação, e espaços originating, dialoguing e exercising. As inovações em produto foram quatro durante o período de tempo estudado, sendo três incrementais (1986-1987, 1988-1989 e 1993-1994) e uma radical (1995). Em todas as inovações de produto, o tipo de aprendizagem foi por interação. Nas incrementais, a forma de aprendizagem foi por single loop, as formas de conversão foram por externalização e combinação, e espaços originating e dialoguing (1986-1987 e 1988-1989) e originating, dialoguing e exercising (1993-1994). Na inovação por produto de 1995, a aprendizagem foi por double loop, houve socialização e os ba foram originating, dialoguing e exercising.

Nas inovações de processo, especificamente em máquinas de fabricação, identificam-se duas inovações radicais (1986-1987 e 1988-1989) e duas incrementais (1993-1994 e 1995). Em todos estes processos de inovação apareceram às aprendizagens pelo fazer, por uso e por pesquisa. Nas inovações radicais, o tipo foi double loop, com as formas de conversão internalização e socialização e espaços originating e dialoguing, enquanto nas incrementais ocorreu o single loop, externalização e combinação, e espaços originating, dialoguing e exercising.

As inovações de processo, especificamente no equipamento de testes e ensaios, foram do tipo incremental, ocorrendo quatro vezes (1986-1987, 1988-1989, 1993-1994 e 1995). Novamente em todas estas inovações os tipos de aprendizagem que se destacaram foram pelo fazer, por uso e por pesquisa. Em todas elas, a aprendizagem foi single loop e as formas de conversão foram externalização e combinação. Quanto aos espaços de interação, foram originating e dialoguing (19861987 e 1988-1989) e originating, dialoguing e exercising (1993-1994 e 1995).

Quanto às inovações de mercado, foram identificadas quatro, sendo três incrementais (1986-1987, 1988-1989 e 1995) e uma radical (1993-1994). Em todas elas emergiu o tipo de aprendizagem por pesquisa. Nas incrementais, o processo de aprendizagem foi por single loop, as formas de conversão do conhecimento externalização e combinação e os espaços, originating e dialoguing (1986-1987 e 1988-1989) e originating, dialoguing e exercising (1995). Já na radical, ocorreu double loop, socialização e originating, dialoguing e exercising. $\mathrm{E}$, em relação às inovações de matéria-prima, as duas ocorrências existentes (1993-1994 e 1995) foram de caráter radical. Nestas, destacaram-se as aprendizagens por interação, por 
uso e por pesquisa. Quanto ao tipo, foi double loop, socialização e espaços originating, dialoguing e exercising.

\section{CONCLUSÕES}

De forma geral, pode-se concluir que as inovações radicais efetuadas pela empresa foco do estudo tenderam a demandar um conjunto maior e diferenciado de aprendizagens (principalmente as pelo fazer, por uso e por pesquisa) se comparadas às inovações incrementais, onde normalmente predominou um único tipo de aprendizagem. Tal fato é corroborado pela literatura, que inter-relaciona aprendizagem organizacional com inovação, com o argumento de que, para a emergência de uma inovação radical, são necessários diversos processos de aprendizagem organizacional.

Um fator interessante que surge neste caso é o das inovações incrementais em processo, seja nas máquinas de fabricação ou no equipamento de testes e ensaio. Imaginava-se que, por tratar-se de pequenas mudanças, o conjunto de aprendizagens necessárias seria menos diferenciado. Mas isto não se mostrou verdadeiro, pois tanto as inovações radicais de processo quanto as de caráter incremental demandaram as aprendizagens por fazer, por uso e por pesquisa. Isto pode ser explicado pelo fato de que em inovações de processo (sejam radicais ou incrementais) diversos aspectos precisam ser verificados, como os equipamentos e máquinas usados para fabricação, o fluxo do processo produtivo e as matériasprimas utilizadas, exigindo uma maior gama de tipos de aprendizagens. Outro resultado desta pesquisa foi à relação entre a tipologia de inovação apresentada e os ciclos de aprendizagem de Argyris e Schön (1978). Pôde-se identificar que, quando há inovações incrementais, a aprendizagem é do tipo single loop e, quando ocorrem inovações radicais, a aprendizagem é por double loop. Isso poderia ser pressuposto a partir da teoria e dos conceitos de cada um desses construtos, mas sua ocorrência num cenário real é digna de nota.

Quanto ao modelo de formas de criação do conhecimento de Nonaka e Takeuchi (1997), verificou-se que, no caso de inovações radicais, predominam a internalização e a socialização. Esses dois modos ocorreram no primeiro período, quando a empresa começou efetivamente a tornar-se mais intensiva em processos 
de inovação. Num segundo momento, contudo, pôde-se perceber que a internalização já não se encontra mais presente, uma vez que o conhecimento tácito em processos de inovação radical já está assimilado pela empresa e o conhecimento explícito já é rotineiro. O que passa a dominar é a socialização, pois apenas aqueles conhecimentos tácitos dos participantes dos projetos é que acontecem com mais freqüência, em situações nas quais se faz necessário o toque pessoal, instintivo, advindo do modelo mental dessas pessoas.

Da mesma forma, nas inovações incrementais, as formas de conversão principais foram a externalização e a combinação. Isso se tornou claro a partir das entrevistas, quando as pequenas melhorias e os ajustes necessários nos processos, a partir de determinado momento, foram dominados por técnicos e engenheiros. Quando isto ocorreu, os procedimentos começaram a ser explicitados e sistematizados (conversão de tácito em explícito) e disponibilizados para uso em outros processos da empresa (explícito em explícito).

Em relação aos espaços de interação, não houve diferenciação de acordo com os tipos de inovação: predominaram o originating e o dialoguing ba. Ou seja, privilegiaram-se encontros face a face para a criação do conhecimento, tanto no nível individual quanto no pessoal. No segundo período (1990-1995), além desses, ocorreu também o espaço exercising, o que se explica pelo uso de meios tecnológicos (no caso, o fax) para troca de informações entre a empresa demandante e a empresa foco do estudo.

Como limitação deste estudo, pode-se citar o pequeno número de entrevistados. A riqueza da pesquisa poderia ser maior, por certo, caso fossem entrevistados participantes desses processos, especialmente alguns do segmento operacional e da Petrobras. Outro fator é o período pesquisado, para o qual a memória dos respondentes já não guarda tantos detalhes. Os pesquisadores pretendem minimizar essa questão concluindo nova versão deste trabalho, que irá considerar dois outros períodos: 1996-2000 e 2001-2005. Mesmo assim, a relevância dos resultados apresentados abre várias possibilidades de pesquisas futuras. Seria instigante acompanhar um ou mais processos de inovação no momento em que se realizassem, de forma a poder aumentar a gama de detalhes e de informações, complementando o método com outras formas de investigação, como observação direta, por exemplo. Alternativa seria a realização de pesquisas do 
tipo survey em um ou mais segmentos, de forma a avaliar a possibilidade de generalização dos resultados. Estudos comparativos entre setores intensivos em inovação também poderiam gerar conclusões de grande interesse científico.

Por fim, sugere-se novos estudos com vistas à confirmação (ou não) de relações surgidas a partir desta pesquisa, como a relação entre inovações incrementais e aprendizagem por single loop e inovações radicais e aprendizagem por double loop, e entre inovações radicais e formas de conversão por internalização e socialização, e inovações incrementais e as conversões por externalização e combinação.

\section{REFERÊNCIAS}

ALLEN, F.; PERCIVAL, J. Financing strategies and venture capital. In: DAY, George S.; SCHOEMAKER, P. J. H.; GUNTHER, Robert E. Wharton on managing emerging technologies. New York: John Wiley and Sons Inc, p. 271-288, 2000.

AMARATUNGA, D., BALDRY, D., SARSHAR, M., NEWTON, R.. Quatitative and qualitative research in the built environment: application of "mixed" research approach, Work Study, Emerald, v, 51, n. 1, p. 17-31, 2002.

ANAND, B.; GALETOVIC, A. Estratégias de mercado podem proteger direitos de propriedade. Harvard Business Review, p. 82-89, dez. 2004.

ANTUNES, J. A. V.; PANTALEÃO, L. H. e PELLEGRIN, I. D. Inovação na cadeia de valor. ENCONTRO NACIONAL DE ENGENHARIA DE PRODUÇÃO, 27. 2007.

Anais... Foz do Iguaçu, 2007.

ANDREW, J. P.; SIRKIN, H. L. Inovar para lucrar. Harvard Business Review, p. 5663, set. 2003.

ARGYRIS, C. On organizational learning. Oxford: Blackwell, 1993.

20, nov./dez.1999.

Aprendizado de duas voltas. HSM Management, São Paulo, p. 12-

ARGYRIS, C. e SCHON, D. Organizational learning. MA: Addison-Wesley, 1978.

BALESTRO, M. V., Características estruturais e mecanismos de governança: apontamentos conceituais. In: VERSCHOORE, J. R. (Org.), Redes de cooperação: uma nova organização de pequenas e médias empresas no Rio Grande o Sul. Porto Alegre: FEE, 2004.

BARDIN, L. Análise de conteúdo. 4. ed. Lisboa: Edições 70, 2008. 
BUKOWITZ, W. R. \& WILLIAMS, R. L. Manual de gestão do conhecimento. Porto Alegre: Bookman, 2002.

CENTER FOR INNOVATION AND BUSINESS DEVELOPMENT - CIDEM. Guide for managing innovation. Barcelona: Department of Industry, Trade and Tourism, 2002.

CHAKRAVORTI, B. Novas regras para lançar uma inovação no mercado. Harvard Business Review, p. 55-63, mar. 2004.

CHAMAS, C. I. Gerenciamento da proteção e exploração econômica da propriedade intelectual. Revista de Administração Pública - RAP, Rio de Janeiro, set./out. 2003.

CHIVA, R.; ALEGRE, J. Organizational learning and organizational knowledge: towards the integration of two approaches. Management Learning, v.36, n. 1, p. 4968, mar. 2005.

CHRISTENSEN, C. M. \& RAYNOR, M. E. O crescimento pela inovação: como crescer de forma sustentada e reinventar o sucesso. Rio de Janeiro: Elsevier, 2003.

CLEGG, S. R.; KORNBERGER, M.; RHODES, C. Learning/Becoming/Organizing. Organization, v. 12, n.2, p. 147-167, mar. 2005.

DAVENPORT, T. H. \& PRUSAK, L. Conhecimento empresarial: como as organizações gerenciam o seu capital intelectual. Rio de Janeiro: Campus, 1998.

DAY, G. S.; SCHOEMAKER, P. J. H. Avoiding the pitfalls of emerging technologies. In: DAY, George S.; SCHOEMAKER, Paul J. H.; GUNTHER, Robert E. Wharton on managing emerging technologies. New York: John Wiley and Sons Inc, 2000. p. 24-52.

DRUCKER, P. F. A disciplina da inovação. Harvard Business Review, p. 80-85, dez. 1985.

DUBÉ, L., PARÉ, Guy, Rigor in Information systems positivist case research: current practices, trends and recommendations. MIS Quaterly, v.27, n.4, p.597-635, 2003.

DYER, J. H. \& SINGH, H. Using alliances to build competitive advantage in Emerging Technologies. In: DAY, G. S.; SCHOEMAKER, P. J. H.; GUNTHER, R. E. Wharton on managing emerging technologies. New York: John Wiley and Sons Inc. 2000. p. $358-375$

EINSENHARDT, K. M. Building theories from case study research. Academy of Management Review. Stanford, v.14, p.532-550, 1989.

ELLRAM, L. M. The use of the case study method in logistics research. Journal of Business Logistics. Arizona, v.17, n.2, p.93-138, 1996. 
FRIEDMAN, V. J.; LIPSHITZ, R.; POPPER, M. The mystification of organizational Learning. Journal of Management Inquiry, v. 14, n.1, p. 19-30, mar. 2005.

GEISLER, E. Inputs to Science and Technology. In: GEISLER, E. The metrics of science and technology. Westport: Quorum Books, 2000. p. 71-96

GODOY, A. S., Introdução à pesquisa qualitativa e suas possibilidades. RAE Revista de Administração de Empresas, v.35, n.2, p.65-71, 1995a.

GODOY, A. S., Pesquisa qualitativa - tipos fundamentais. RAE - Revista de Administração de Empresas, v.35, n.3, p.20-29, 1995b.

GOLDENBERG, J.; MAZURSKY, D. Creativity in product innovation. Boston: Cambridge University Press, 2001.

GOLDENBERG, J.; HOROWITZ, R.; LEVAV, A.; MAZURSKY, D. Inovação no ponto certo. Harvard Business Review, p. 84-92, mar. 2003.

HAMEL, G. \& GETZ, G. Financiando a inovação numa era de austeridade. Harvard Business Review, p. 10-18, ago. 2004.

HAMILTON, W. F. Managing real options. In: DAY, G. S.; SCHOEMAKER, P. J. H.; GUNTHER, R. E. Wharton on managing emerging technologies. New York: John Wiley and Sons Inc, p. 271-288, 2000.

HAMMER, M. Mudança profunda: como a inovação operacional pode transformar sua empresa. Harvard Business Review, p. 46-54, abr. 2004.

KANTER, R. M. The Change Masters: Innovation for Productivity in the American Mode. New York: Simon \& Schuster, 1983.

KIM, W. C.; MAUBORGNE, R. Inovação de valor: a lógica estratégica do alto crescimento. Harvard Business Review, p. 98-106, abr. 1997.

LOIOLA, E.; ROCHA. M. C. F; RASKIN, S. Microprocesso de aprendizagem: o caso da delimitação da metodologia para avaliação e seleção de ferramenta case para o Estado da Bahia. . In: ENANPAD, 2002. Salvador, BA. Anais... 2002, v.1, p.1-15.

LOIOLA, E.; ROCHA. M. C. F. Aprendizagem no processo de seleção de ferramenta case para o Estado da Bahia. Revista de Administração Contemporânea (RAC), v.6, n.2, p. 145-166, maio/ago. 2002.

MALERBA, F. Learning by firms and incremental technical change. The Economic Journal, v. 102, n. 413, p. 845-859, jul. 1992.

MILLER, W. L.; MORRIS, L.. Fourth geration R\&D: managing knowledge, technology and innovation. USA/Canada: John Wiley \& Sons Inc, 1998.

MOORE, G. A. Darwin e o demônio: a inovação em empresas estabelecidas. Harvard Business Review, p. 20-26, ago. 2004. 
NONAKA, I; KONNO, N. The concept of ba: building a foundation for knowledge creation. California Management Review, Berkeley, v. 40, n.3, p. 40-54, 1998.

NONAKA, I; TAKEUCHI, H. Criação de conhecimento na empresa: como as empresas japonesas geram a dinâmica da inovação. Rio de Janeiro: Campus, 1997.

NONAKA, I; TOYAMA, R; KONNO, N. SECI, Ba and leadership: a unified model of dynamic knowledge creation. Long Range Planning, n.33, p. 5-34, 2000.

OECD - Organization for Economic Cooperation and Development. Manual de Oslo/EUROESTAT, 1997.

OSONO, E.; SHIMIZU, N.; TAKEUCHI, H. Relatório toyota: contradições responsáveis pelo sucesso da maior montadora do mundo. Rio de Janeiro: Ediouro, 2008.

PERIN, M. G.; SAMPAIO, C. H.; FALEIRO, S. N. A Relação entre orientação para o mercado, orientação para aprendizagem e inovação de produto. In: ENANPAD, 2002, Salvador, BA. Anais.... Salvador, 2002, v.1, p.1-15.

PRANGE, C. Aprendizagem organizacional: desesperadamente em busca de teorias? In: EASTHERBY-SMITH, M; ARAUJO, L.; BURGOYNE, J. Aprendizagem organizacional e organização de aprendizagem. São Paulo: Atlas, 2001.

PROBST, G.; RAUB, S.; ROMHARDT, K. Gestão do conhecimento: os elementos construtivos do sucesso. Porto Alegre: Bookman, 2002.

ROBERTS, E. Managing creativity and Innovation. In: Harvard business essentials. Massachusets: Harvard Business School Press, 2003. Cap. 5.

ROESCH, S. M. A. Projetos de estágio e de pesquisa em administração: guia para estágios, trabalhos de conclusão, dissertações e estudos de caso. 2 ed. São Paulo: Atlas, 1999.

RUELAS-GOSSI, A. O paradigma do T grande. Harvard Business Review, p. 5258 , fev. 2004.

SCHEFFER, J. R.; SCHENINI, P. C. Processos de aprendizagem e regime tecnológico na indústria de móveis do arranjo produtivo moveleiro da região de São Bento do Sul (SC): um estudo de caso em empresas selecionadas. In: ENANPAD, 2004, Curitiba, PR. Anais... Curitiba, 2004, v.1, p.1-15.

SCHOEMAKER, P. J. H. \& SHAPIRO, A. C. Innovative financial strategies for biotechnology ventures. In: DAY, G. S.; SCHOEMAKER, P. J. H.; GUNTHER, R. E. Wharton on managing emerging technologies. New York: John Wiley and Sons, 2000. p. 307-332,.

SCHUMPETER, J. A. Capitalismo, socialismo e democracia. Rio de Janeiro: Fundo de Cultura, 1961. 
SHANLEY, R. P. Financing technology's frontier: decision-making models for investors and advisors. New York: John Wiley \& Sons, 1998. cap. 1-3, p. 1-49.

SIMANTOB, M. \& LIPPI, R. Guia valor econômico de inovação nas empresas. São Paulo: Globo, 2003.

SVEIBY, K. E. A nova riqueza das organizações: gerenciando e avaliando patrimônios do conhecimento. Rio de Janeiro: Campus, 1998.

THOMKE, S. Experimentation matters: unlocking the potential of new technologies for innovation. Boston: Harvard Business School Press, 2003.

TRIPSAS, M. Commercializing emerging technology through complementary Assets. In: DAY, George S.; SCHOEMAKER, Paul J. H.; GUNTHER, Robert E. Wharton on managing emerging technologies. New York: John Wiley and Sons Inc, p. 172186, 2000.

TSANG, E. W. K. Organizational learning and the learning organization: a Dichotomy between Descriptive and Prescriptive Research. Human Relations, v. 50, n.1, p. 7389, 1997.

VERGARA, Sylvia Constant, Métodos de pesquisa em administração. São Paulo: Atlas, 2007.

WOOD, R. C.; HAMEL, G. O mercado de inovações do banco mundial. Harvard Business Review, p. 80-86, nov. 2002.

YIN, R. K. Estudos de caso: planejamento e métodos. 3. ed. Porto Alegre: Bookman, 2005.

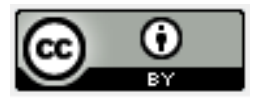

Artigo recebido em 25/08/2010 e aceito para publicação em 10/04/2011. 